\title{
Comparison of a dietary record using reported portion size versus standard portion size for assessing nutrient intake
}

\author{
Desiree C Welten ${ }^{1}$, Ruth A Carpenter ${ }^{1}$, R Sue McPherson ${ }^{2}$, Suzanne Brodney ${ }^{2}$, \\ Deirdre Douglass ${ }^{2}$, James B Kampert ${ }^{1}$ and Steven N Blair ${ }^{1, *}$ \\ ${ }^{1}$ The Cooper Institute, 12330 Preston Road, Dallas, TX 75230, USA: \\ ${ }^{2}$ University of Texas, Houston School of Public Health, Houston, TX 75225, USA
}

Submitted 15 April 1999: Accepted 28 September 1999

\begin{abstract}
Objective: Because the percentage of missing portion sizes was large in the Aerobics Center Longitudinal Study (ACLS), careful consideration of the accuracy of standard portion sizes was necessary. The purpose of the present study was to investigate the consequences of using standard portion sizes instead of reported portion sizes on subjects' nutrient intake.

Methods: In 2307 men and 411 women, nutrient intake calculated from a 3-day dietary record using reported portion sizes was compared with nutrient intake calculated from the same record in which standard portion sizes were substituted for reported portion sizes.

Results: The standard portion sizes provided significantly lower estimates ( $\geqslant 20 \%)$ of energy and nutrient intakes than the reported portion sizes. Spearman correlation coefficients obtained by the two methods were high, ranging from 0.67 to 0.93 . Furthermore, the agreement between both methods was fairly good. Thus, in the ACLS the use of standard portion sizes rather than reported portion sizes did not appear to be suitable to assess the absolute intake at the group level, but appeared to lead to a good ranking of individuals according to nutrient intake. These results were confirmed by the Continuing Survey of Food Intake by Individuals (CSFII), in which the assessment of the portion size was optimal. When the standard portion sizes were adjusted using the correction factor, the ability of the standard portion sizes to assess the absolute nutrient intake at the group level was considerably improved.

Conclusions: This study suggests that the adjusted standard portion sizes may be able to replace missing portion sizes in the ACLS database.
\end{abstract}

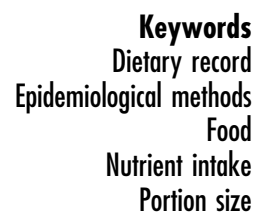

In nutritional epidemiology studies, minimizing measurement error is a key element in the successful elucidation of diet-disease relationships. One of the main errors in the assessment of nutrient intake occurs during the determination of portion size. Where information about portion size is missing, standard portion sizes have traditionally been used. This assumes that standard portion sizes accurately reflect the amount typically consumed. However, findings on the accuracy of standard portions are conflicting ${ }^{1-8}$.

As part of the large-scale observational ACLS, dietary intake was assessed using the dietary record method. Information about portion size was obtained by estimating the amount for each food consumed. However, for many food items information on portion size was not available. Since the percentage of missing portion sizes was large (22\%), this prompted the need to determine whether standard portion sizes were able to replace missing portion sizes in the ACLS data set.

The aim of the present study is to investigate in the ACLS database the consequences of using standard portion sizes instead of reported portion sizes on subjects' nutrient intakes. Furthermore, we evaluated the effect of substituting standard portion sizes for reported portion sizes on nutrient intake in the 1994 CSFII. The 1994 CSFII was a nationwide food survey in which an optimal assessment of the portion size was implemented in the design of the study (only $1 \%$ of portion sizes were missing). The results of the CSFII data enable us to estimate more accurately whether standard portion sizes reflect the actual portion size. This paper presents the results of both comparison studies and consequent modifications of the standard portion size introduced to improve its comparability.

\section{Methods}

\section{Aerobics Center Longitudinal Study}

Subjects and design

The ACLS is a prospective observational study of a large group of men and women who received a preventive 
medical examination at least once during 1970-1995 at the Cooper Clinic in Dallas, Texas. Study participants were primarily self-referred and typically were well educated (approximately 80\% were college graduates), white (>97\%) and from middle and upper socioeconomic strata. Examinations included a medical history questionnaire, physical examination, anthropometry, electrocardiography, blood chemistry analyses, blood pressure measurement and a maximal exercise treadmill test, in addition to dietary assessment.

The population for this study was composed of first-visit participants who ranged in age from 20 to 80 years and had their dietary assessment between 1987 and 1995. We intended to include only those participants who had no missing portion sizes in their 3-day diet records (method described further below). However, nearly all subjects had one or more missing portion sizes in their 3-day diet records, which meant that almost none of the subjects remained in the study. Therefore, we decided to handle the 3-day records as three separate 1-day records. We proceeded in the following manner: if two out of three 1-day records had missing portion sizes, but the third 1-day had no missing values, only this third 1-day record was included in the study. If one out of three 1-day records had missing values, only the other two 1-day records were included in the study. If none of the three 1-day records had missing portion sizes, all three 1 -day records were included. However, including separate 1-day records in the study might influence the comparison of reported versus standard portions because these records are not independent of each other. Therefore, for each subject the average of the separate 1-day records was used for those with 2 or 3 days of records.

A total of 24458 one-day diet records were available in men, and 7665 one-day diet records in women. Of these, $87 \%$ of the 1-day records in men and $93 \%$ in women were excluded because of missing portion sizes. Therefore, this study comprised 3072 one-day diet records for men and 499 one-day records for women, which were obtained from 2307 men (average age, 46 years; SD 9.5) and 411 women (average age, 43 years; SD 11). Only 6\% of the men and $3 \%$ of the women had all three 1 -day diet records available for the study.

\section{Dietary assessment}

Food intake information was obtained by a 3-day dietary record, including 2 week days and 1 weekend day. The record was an open-ended (unstructured) estimated diet record. This 3-day diet record, together with written instructions, was sent to the participants several weeks prior to their visit to the Cooper Clinic. The instructions included helpful tips for accurately describing foods and estimating portion sizes. Subjects kept a written record of foods consumed during meals as well as between meals at the time of eating, and assessed portion sizes in common household measures. After completion of the diet record, it was returned to the Cooper Clinic by post or brought to the clinic at the time of the examination. Intakes of dietary components were calculated from the food intake data by using the Food Intake Analysis System (FIAS) ${ }^{9}$.

\section{Statistical analyses}

The analyses were performed for two types of comparisons in each sex. First, nutrient intake calculated from the dietary record using reported portion sizes was compared with nutrient intake calculated from the same record in which standard portion sizes were substituted for reported portion sizes. 'Quantity not specified' (QNS) serving sizes from the Survey Nutrient Database were used as the standard portion sizes. The QNS servings are based on the most commonly consumed portion sizes obtained from the US Department of Agriculture (USDA) data.

Second, in order to improve the comparability, the same comparison was conducted as above, but adjusted standard portion sizes were used. The standard portion sizes were adjusted for energy intake by multiplying the QNS serving sizes of each food with a correction factor. This factor was based on the ratio of the mean energy intake from reported portion sizes to the mean energy intake from standard portion sizes and was different for males and females. Thus, nutrient intake obtained from reported portion sizes was compared with nutrient intake obtained from adjusted standard portion sizes.

For both comparisons, the ability to assess the absolute intake at the group level as well as the ability to correctly rank individuals according to nutrient intake was evaluated. To assess the absolute intake at the group level, means and mean differences with 95\% confidence intervals (CI) were calculated for each nutrient. In order to assess the ability to rank individuals, Spearman's product-moment correlation coefficients for each nutrient were calculated between pairwise measurements. Furthermore, as a measure of ranking, the agreement between nutrient intakes obtained from pairwise measurements was evaluated. The nutrient intakes were divided into quintiles separately for each measurement. Then the percentage exact agreement, the per cent adjacent agreement, and the percentage of extreme misclassification was assessed between both measurements. For all statistical analyses, the software package SAS (version 6.12) was used ${ }^{10}$.

\section{Continuing Survey of Food Intake by Individuals}

\section{Subjects and design}

The 1994-1996 CSFII is the 10th nationwide food survey conducted by USDA. The present study contains information from the 1994 CSFII, which includes only the first year of data collected during the 3 years of the 1994-1996 CSFII. Each of the CSFII survey years comprises a nationally representative sample of non-institutionalized persons residing in households in the USA for each of 
40 domains defined by sex, age (10 age groups) and income level. The 1994-1996 CSFII sample is a stratified, multistage area probability sample. Sample persons were selected through a complex four-stage sample design involving the selection of primary sampling units (PSUs) consisting of counties, area segments within PSUs, households within segments, and finally sample persons within households. The stratification plan took into account geographic location, degree of urbanization and socioeconomic characteristics. A detailed description of the sample design is available in an earlier publication ${ }^{11}$.

The 1994 CSFII collected data on food and nutrient intakes from individuals of all ages. In the present study, only persons between 20 and 80 years of age were included, as in the ACLS study. Furthermore, the population for this study was composed of persons who had no missing portion sizes in their two 1-day recalls (method described below). We eliminated any day of intake in which information on portion size was not available for a food item. A total of 3063 days of intake were available for men, and 3050 days of intake for women. Of these, $17 \%$ of those days were excluded in men and 15\% in women because of missing portion sizes. Therefore, this study consists of 2538 days of intake in men and 2581 days of intake in women, which represent 1504 men (average age, 47 years; SD 16) and 1504 women (average age, 47 years; SD 16). The percentage of subjects with two complete 1 -day recalls was $69 \%$ in men and $72 \%$ in women.

\section{Dietary assessment}

In the 1994 CSFII, two non-consecutive days of dietary data were collected between mid-January 1994 and midJanuary 1995 using a 1-day recall in an in-person interview. The second interview was conducted 3-10 days after the first interview but not on the same day of the week. The 1-day dietary recall was administered by asking the subject to report everything (s)he ate or drank the previous day between midnight and midnight. The interviewer used a food instruction booklet to probe for a complete description of every food item. Under each appropriate category of food/drink listed in the booklet, there was a list of questions the interviewer was required to ask in order to collect enough detail for the food to be coded. For example, questions were asked about brand name, ingredients, additions and the use of fat in food preparations. The portion sizes were reported in household measures. Measuring guides used to aid the subject in estimating portion sizes were household measuring cups and spoons, a 12-inch $(30 \mathrm{~cm})$ ruler, thickness sticks and a laminated card printed with concentric circles. Food consumption data were converted into energy and nutrients by using the FIAS, which was also used in the ACLS.

\section{Statistical analyses}

The analyses were performed for the comparison of nutrient intake calculated from the dietary recall using reported portion sizes and nutrient intake calculated from the same dietary recall in which standard portion sizes were substituted for reported portion sizes. The standard portion sizes were derived from the same set of QNS serving sizes as mentioned above in the ACLS. The comparison was evaluated at two levels: the ability to assess the absolute intake at the group level and the ability to correctly rank individuals according to nutrient intake. To assess the absolute intake at the group level as well as the ranking of individuals according to nutrient intake, the same statistical methods were used as described in the ACLS.

\section{Results}

\section{Aerobics Center Longitudinal Study}

Means and mean differences in energy and nutrient intake obtained by reported, standard and adjusted standard portion sizes are presented in Tables $1 \mathrm{a}$ and b. As shown in these tables, the reported portion size provides consistently higher intakes of energy and nutrients than the standard portion size in men as well as in women. The differences in energy and nutrient intake between reported and standard portion size varied from 33\% (for polyunsaturated fatty acids (PUFA) and calcium to $50 \%$ (for alcohol) in men, and from 20\% (for calcium) to $43 \%$ (for alcohol) in women. All differences were significant as demonstrated by the $95 \% \mathrm{CI}$.

When the energy and nutrient intake obtained by reported portion sizes was compared with the energy and nutrient intake obtained by adjusted standard portion sizes, the discrepancy between the measured intakes of the two methods was largely reduced in men as well as in women. The differences ranged between 0.03\% (for energy) and 11\% (for carotene) in men, and between $-0.06 \%$ (for energy) and 13\% (for carotene) in women. The difference was above $20 \%$ only for alcohol intake. Of the 18 dietary components in Table 1 , there was a significant difference in intake between reported and adjusted standard portion size for 10 nutrients (saturated fatty acids (SFA), monounsaturated fatty acids (MUFA), PUFA, carbohydrates, alcohol, carotene, thiamin, riboflavin, vitamin $\mathrm{B}_{6}$ and calcium) in men and for seven nutrients (MUFA, alcohol, carotene, riboflavin, vitamins $\mathrm{B}_{6}$ and $\mathrm{C}$ and calcium) in women. For the macronutrients, the reported portion size provided generally higher values than the adjusted standard portion size, while for the micronutrients the opposite was true in most cases.

Spearman correlation coefficients and quintile analyses between nutrient intakes obtained by reported and standard portion sizes are presented in Tables $2 \mathrm{a}$ and $\mathrm{b}$. The Spearman correlation coefficients for energy and nutrient intakes varied from 0.67 (for protein) to 0.92 (for carotene) in men, and from 0.71 (for protein) to 0.93 (for carotene) in women. The per cent exact agreement for energy and nutrient intakes ranged from 40\% (for energy 
Table 1a Mean difference of the energy and nutrient intake obtained by reported portion size and (adjusted) standard portion size in male ACLS participants $(n=2307)$

\begin{tabular}{|c|c|c|c|c|c|c|c|c|c|c|c|c|}
\hline & \multicolumn{2}{|c|}{$\begin{array}{l}\text { Reported } \\
\text { portion size }\end{array}$} & \multicolumn{2}{|c|}{$\begin{array}{l}\text { Standard } \\
\text { portion size }\end{array}$} & \multicolumn{2}{|c|}{$\begin{array}{l}\text { Adjusted standard } \\
\text { portion size* }\end{array}$} & \multicolumn{3}{|c|}{$\begin{array}{l}\text { Difference } \\
\text { reported (standard) }\end{array}$} & \multicolumn{3}{|c|}{$\begin{array}{l}\text { Difference } \\
\text { reported (adjusted standard) }\end{array}$} \\
\hline & Mean & SD & Mean & SD & Mean & SD & Mean & $\% \dagger$ & $95 \% \mathrm{Cl}$ & Mean & $\% \dagger$ & $95 \% \mathrm{Cl}$ \\
\hline Energy (kcal) & 2015 & 806 & 1248 & 411 & 2014 & 664 & 767 & 38 & $742 ; 793$ & 0.62 & 0.03 & $-25 ; 26$ \\
\hline Protei & 90 & 39 & 55 & 20 & 89 & 33 & 35 & 3 & $33 ; 36$ & 0.67 & 0.74 & $-0.57 ; 1.9$ \\
\hline Total fat $(\mathrm{g})$ & 79 & 42 & 49 & 22 & 79 & 35 & 31 & 39 & $29 ; 32$ & 0.7 & 0.95 & $-0.48 ; 2.0$ \\
\hline SFA (g) & 26 & 16 & 16 & 8.1 & 25 & 13 & 10 & 38 & $9.7 ; 11$ & 0.53 & 2.0 & $0.10 ; 0.96$ \\
\hline MUFA (g) & 31 & 18 & 19 & 8.6 & 30 & 14 & 13 & 42 & $12 ; 13$ & 1.4 & 4.5 & $0.90 ; 1.9$ \\
\hline PUFA (g) & 16 & 9.4 & 11 & 5.7 & 17 & 9 & 5.2 & 33 & $4.9 ; 5.4$ & -1.3 & -8.1 & $-1.6 ;-1.0$ \\
\hline Cholesterol (mg) & 274 & 199 & 167 & 108 & 269 & 174 & 107 & 39 & $101 ; 112$ & 4.0 & 1.5 & $-0.9 ; 8.9$ \\
\hline hydrate (g) & 221 & 115 & 141 & 59 & 228 & 95 & 80 & 36 & $76 ; 83$ & -7.0 & -3.2 & $-11 ;-3.4$ \\
\hline Fibre & 16 & 10 & 10 & 5.5 & 16 & 8.8 & 6.3 & 39 & $6.1 ; 6.6$ & 0.15 & 0.94 & $-0.12 ; 0.43$ \\
\hline Alcohol (g) & 12 & 20 & 5.6 & 8.6 & 9.0 & 14 & 6.0 & 50 & $5.4 ; 6.6$ & 2.6 & 22 & $2.1 ; 3.1$ \\
\hline Vitamin $\mathrm{A}(\mu \mathrm{g} \mathrm{RE})$ & 1021 & 1666 & 637 & 634 & 1029 & 1023 & 384 & 38 & $325 ; 442$ & -8.0 & -0.78 & $-66 ; 50$ \\
\hline$(\mu \mathrm{g} R \mathrm{E})$ & 522 & 1519 & 288 & 426 & 465 & 688 & 234 & 45 & $178 ; 290$ & 57 & 11 & $2.0 ; 112$ \\
\hline Thiamin (mg) & 1.6 & 0.84 & 1.0 & 0.51 & 1.6 & 0.83 & 0.59 & 37 & $0.57 ; 0.61$ & -0.03 & -1.9 & $-0.06 ;-0.01$ \\
\hline Ribofla & 1.9 & 0.94 & 1.2 & 0.63 & 2.0 & 1.0 & 0.67 & 35 & $0.64 ; 0.69$ & -0.08 & -4.2 & $-0.11 ;-0.05$ \\
\hline Vitamin $B_{6}(\mathrm{mg})$ & 2.0 & 1.1 & 1.3 & 0.72 & 2.1 & 1.2 & 0.67 & 34 & $0.64 ; 0.70$ & -0.13 & -6.5 & $-0.17 ;-0.10$ \\
\hline Vitamin C (mg) & 99 & 225 & 64 & 53 & 103 & 85 & 35 & 35 & $26 ; 43$ & -4.8 & -4.8 & $-13 ; 3.8$ \\
\hline Calcium (mg) & 750 & 458 & 504 & 294 & 813 & 475 & 247 & 33 & $234 ; 259$ & -63 & -8.4 & $-76 ;-49$ \\
\hline Iron (mg) & 16 & 10 & 9.8 & 6.2 & 16 & 10 & 6.2 & 39 & $5.9 ; 6.5$ & 0.17 & 1.1 & $-0.11 ; 0.44$ \\
\hline
\end{tabular}

* Adjusted standard portion size $=$ standard portion size $\times$ correction factor; correction factor $=2015$ (mean energy intake for reported portion size)/1248 (mean energy intake for standard portion size).

†Difference as percentage of the nutrient intake obtained by reported portion size.

Table 1b Mean difference of the energy and nutrient intake obtained by reported portion size and (adjusted) standard portion size in female ACLS participants $(n=411)$

\begin{tabular}{|c|c|c|c|c|c|c|c|c|c|c|c|c|}
\hline & \multicolumn{2}{|c|}{$\begin{array}{l}\text { Reported } \\
\text { portion size }\end{array}$} & \multicolumn{2}{|c|}{$\begin{array}{l}\text { Standard } \\
\text { portion size }\end{array}$} & \multicolumn{2}{|c|}{$\begin{array}{l}\text { Adjusted standard } \\
\text { portion size } e^{\star}\end{array}$} & \multicolumn{3}{|c|}{$\begin{array}{l}\text { Difference } \\
\text { reported (standard) }\end{array}$} & \multicolumn{3}{|c|}{$\begin{array}{l}\text { Difference } \\
\text { reported (adjusted standard) }\end{array}$} \\
\hline & Mean & SD & Mean & SD & Mean & SD & Mean & $\% \dagger$ & $95 \% \mathrm{Cl}$ & Mean & $\% \dagger$ & $95 \% \mathrm{Cl}$ \\
\hline Energy (kcal) & 1475 & 661 & 1078 & 389 & 1476 & 532 & 396 & 27 & $350 ; 443$ & -0.90 & -0.06 & $-48 ; 46$ \\
\hline Protein (g) & 64 & 29 & 48 & 21 & 65 & 28 & 16 & 25 & $14 ; 18$ & -1.6 & -2.5 & $-3.7 ; 0.46$ \\
\hline Total fat $(\mathrm{g})$ & 57 & 36 & 41 & 21 & 55 & 28 & 17 & 30 & $14 ; 19$ & 1.7 & 3.0 & $-0.64 ; 4.0$ \\
\hline SFA (g) & 18 & 13 & 13 & 7.5 & 18 & 10 & 5.4 & 30 & $4.6 ; 6.3$ & 0.63 & 3.5 & $-0.22 ; 1.5$ \\
\hline MUFA $(\mathrm{g})$ & 22 & 15 & 15 & 8.1 & 21 & 11 & 7.1 & 32 & $6.1 ; 8.1$ & 1.5 & 6.8 & $0.54 ; 2.5$ \\
\hline PUFA (g) & 12 & 8.4 & 9.1 & 5.7 & 12 & 7.8 & 2.8 & 23 & $2.2 ; 3.4$ & -0.57 & -4.8 & $-1.1 ; 0.01$ \\
\hline Cholesterol (mg) & 194 & 161 & 143 & 107 & 196 & 147 & 51 & 26 & $42 ; 60$ & -1.8 & -0.93 & $-11 ; 7.2$ \\
\hline Carbohydrate (g) & 172 & 87 & 129 & 52 & 177 & 72 & 43 & 25 & $37 ; 49$ & -4.4 & -2.6 & $-11 ; 1.7$ \\
\hline Fibre $(\mathrm{g})$ & 13 & 8.2 & 9.4 & 5.4 & 13 & 7.4 & 4.0 & 31 & $3.5 ; 4.5$ & 0.49 & 3.8 & $-0.03 ; 1.0$ \\
\hline Alcohol (g) & 5.6 & 13 & 3.2 & 6.9 & 4.4 & 9.4 & 2.4 & 43 & $1.5 ; 3.2$ & 1.2 & 21 & $0.43 ; 2.0$ \\
\hline Vitamin $A(\mu \mathrm{g} R \mathrm{E})$ & 871 & 1085 & 636 & 701 & 870 & 959 & 236 & 27 & 173; 299 & 1.5 & 0.17 & $-59 ; 62$ \\
\hline Carotene ( $\mu \mathrm{g} \mathrm{RE})$ & 455 & 848 & 291 & 425 & 398 & 581 & 164 & 36 & $107 ; 221$ & 57 & 13 & $4.2 ; 110$ \\
\hline Thiamin (mg) & 1.2 & 0.67 & 0.89 & 0.53 & 1.2 & 0.73 & 0.30 & 25 & $0.26 ; 0.34$ & -0.03 & -2.5 & $-0.07 ; 0.02$ \\
\hline Riboflavin (mg) & 1.5 & 0.84 & 1.1 & 0.68 & 1.5 & 0.94 & 0.33 & 22 & $0.28 ; 0.38$ & -0.09 & -6.0 & $-0.14 ;-0.03$ \\
\hline Vitamin $B_{6}(\mathrm{mg})$ & 1.5 & 0.87 & 1.2 & 0.73 & 1.6 & 0.99 & 0.31 & 21 & $0.26 ; 0.36$ & -0.12 & -8.0 & $-0.17 ;-0.07$ \\
\hline Vitamin $C(\mathrm{mg})$ & 79 & 77 & 62 & 54 & 85 & 74 & 17 & 22 & $13 ; 21$ & -6.4 & -8.1 & $-10 ;-2.6$ \\
\hline Calcium (mg) & 598 & 397 & 479 & 319 & 655 & 437 & 119 & 20 & $94 ; 144$ & -57 & -9.5 & $-85 ;-29$ \\
\hline Iron (mg) & 12 & 8.1 & 8.7 & 6.2 & 12 & 8.5 & 3.3 & 28 & $2.8 ; 3.8$ & 0.10 & 0.83 & $-0.41 ; 0.61$ \\
\hline
\end{tabular}

${ }^{*}$ Adjusted standard portion size = standard portion size $\times$ correction factor; correction factor=1475 (mean energy intake for reported portion size)/1078 (mean energy intake for standard portion size).

† Difference as percentage of the nutrient intake obtained by reported portion size.

and protein) to $64 \%$ (for carotene) in men, and from $43 \%$ (for protein) to $66 \%$ (for vitamin C) in women. The percentage of those subjects who were correctly classified in the same or adjacent quintile by both measurements was between $80 \%$ (for protein) and 97\% (for carotene and vitamin C) in men, and between 81\% (for protein) and 98\% (for carotene) in women. The proportion of individuals extremely misclassified was close to zero $(0.0-0.8 \%$ in men, $0.0-0.5 \%$ in women).

For the comparison of energy and nutrient intake using reported and adjusted standard portion sizes, the same correlation coefficients and agreement statistics were found as for the comparison of energy and nutrient intake using reported and standard portion sizes because the adjusted standard portion sizes were calculated by multiplying the standard portion sizes with a constant value.

\section{Continuing Survey of Food Intake by Individuals}

Tables $3 \mathrm{a}$ and $\mathrm{b}$ show means and mean differences for energy and nutrient intake using reported and standard 
Table 2a Spearman correlation coefficients and quintile analyses between energy and nutrient intakes obtained by the reported portion size and by the (adjusted) standard portion size in male ACLS participants $(n=2307)$

\begin{tabular}{lcccc}
\hline & $\begin{array}{c}\text { Spearman correlation } \\
\text { coefficients }\end{array}$ & Same quintile (\%) & $\begin{array}{c}\text { Same + adjacent } \\
\text { quintile (\%) }\end{array}$ & Extreme quintile (\%) \\
\hline Energy (kcal) & 0.69 & 40 & 82 & 0.8 \\
Protein (g) & 0.67 & 40 & 80 & 0.4 \\
Total fat (g) & 0.78 & 46 & 87 & 0.2 \\
SFA (g) & 0.83 & 51 & 91 & 0.1 \\
MUFA (g) & 0.79 & 47 & 88 & 0.1 \\
PUFA (g) & 0.79 & 48 & 89 & 0.2 \\
Cholesterol (mg) & 0.83 & 52 & 91 & 0.1 \\
Carbohydrate (g) & 0.78 & 47 & 88 & 0.4 \\
Fibre (g) & 0.82 & 51 & 91 & 0.2 \\
Vitamin A $(\mu \mathrm{g} \mathrm{RE})$ & 0.89 & 59 & 96 & 0.1 \\
Carotene $(\mu \mathrm{g} \mathrm{RE})$ & 0.92 & 64 & 97 & 0.0 \\
Thiamin $(\mathrm{mg})$ & 0.79 & 48 & 88 & 0.2 \\
Riboflavin $(\mathrm{mg})$ & 0.80 & 48 & 89 & 0.2 \\
Vitamin B $(\mathrm{mg})$ & 0.80 & 60 & 89 & 0.3 \\
Vitamin C (mg) & 0.91 & 51 & 97 & 0.0 \\
Calcium $(\mathrm{mg})$ & 0.81 & 49 & 90 & 0.3 \\
Iron $(\mathrm{mg})$ & 0.79 & & 88 & 0.1 \\
\hline
\end{tabular}

Table 2b Spearman correlation coefficients and quintile analyses between energy and nutrient intakes obtained by the reported portion size and by the (adjusted) standard portion size in female ACLS participants $(n=411)$

\begin{tabular}{lcccc}
\hline & $\begin{array}{c}\text { Spearman correlation } \\
\text { coefficients }\end{array}$ & Same quintile (\%) & $\begin{array}{c}\text { Same +adjacent } \\
\text { quintile (\%) }\end{array}$ & Extreme quintile (\%) \\
\hline Energy (kcal) & 0.73 & 44 & 84 & 0.5 \\
Protein $(\mathrm{g})$ & 0.71 & 43 & 81 & 0.0 \\
Total fat $(\mathrm{g})$ & 0.81 & 51 & 90 & 0.2 \\
SFA $(\mathrm{g})$ & 0.85 & 51 & 93 & 0.0 \\
MUFA $(\mathrm{g})$ & 0.81 & 46 & 90 & 0.0 \\
PUFA $(\mathrm{g})$ & 0.82 & 53 & 90 & 0.0 \\
Cholesterol $(\mathrm{mg})$ & 0.89 & 58 & 94 & 0.0 \\
Carbohydrate $(\mathrm{g})$ & 0.79 & 50 & 88 & 0.2 \\
Fibre $(\mathrm{g})$ & 0.84 & 54 & 92 & 0.0 \\
Vitamin A $(\mu \mathrm{g} \mathrm{RE})$ & 0.89 & 62 & 96 & 0.0 \\
Carotene $(\mu \mathrm{g} \mathrm{RE})$ & 0.93 & 49 & 98 & 0.3 \\
Thiamin $(\mathrm{mg})$ & 0.82 & 52 & 91 & 0.0 \\
Riboflavin $(\mathrm{mg})$ & 0.82 & 52 & 90 & 0.5 \\
Vitamin $\mathrm{B}_{6}(\mathrm{mg})$ & 0.83 & 66 & 90 & 0.0 \\
Vitamin C $(\mathrm{mg})$ & 0.91 & 60 & 97 & 0.0 \\
Calcium $(\mathrm{mg})$ & 0.85 & 48 & 93 & 0.0 \\
Iron $(\mathrm{mg})$ & 0.82 & & 89 & \\
\hline
\end{tabular}

portion sizes in the CSFII population. For energy as well as for all nutrients, the reported portion size provided significantly higher intakes than the standard portion size in both sexes. The differences ranged between 28\% (for carotene and calcium) and 39\% (for iron) in men, and between 6\% (for calcium) and 20\% (for carbohydrate and iron) in women. For alcohol intake, the difference was above $50 \%$ in both sexes.

Spearman correlation coefficients between energy and nutrient intakes using reported versus standard portion sizes varied from 0.61 (for protein) to 0.91 (for carotene) in men, and from 0.67 (for protein) to 0.92 (for carotene) in women (Tables $4 \mathrm{a}$ and b). Percentage exact agreement was between 38\% for energy and 61\% for carotene in men and between $42 \%$ (for energy and protein) and 60\% (for carotene) in women, and the percentage agreement in the same or adjacent quintile was between $77 \%$ (for protein) and $97 \%$ (for carotene) in men and between $81 \%$ (for energy and protein) and 98\% (for carotene) in women. The percentage of subjects extremely misclassified was close to zero $(0.0-1.0 \%$ in men, $0.0-0.9 \%$ in women) (Table 4).

\section{Discussion}

In the ACLS, careful consideration of the accuracy of standard portion sizes was necessary because the percentage of missing portion sizes was large (22\%). One probable explanation for such a high percentage could be that the dietary records were not reviewed with participants after the recording period. Furthermore, the participants were given written instructions by post instead of in-person instructions on how to fill in the diet records. The purpose of the present study was to investigate the 
Table 3a Mean difference of the energy and nutrient intake obtained by reported portion size and standard portion size in male CSFII participants $(n=1504)$

\begin{tabular}{|c|c|c|c|c|c|c|c|}
\hline & \multicolumn{2}{|c|}{ Reported portion size } & \multicolumn{2}{|c|}{ Standard portion size } & \multicolumn{3}{|c|}{ Difference* $^{*}$} \\
\hline & Mean & SD & Mean & SD & Mean & $\% †$ & $95 \% \mathrm{Cl}$ \\
\hline Energy (kcal) & 2310 & 942 & 1448 & 476 & 862 & 37 & $824 ; 900$ \\
\hline Protein (g) & 92 & 40 & 61 & 22 & 32 & 35 & 30; 33 \\
\hline Total fat $(\mathrm{g})$ & 88 & 45 & 56 & 23 & 32 & 36 & $30 ; 34$ \\
\hline SFA (g) & 30 & 16 & 19 & 8.4 & 10 & 33 & $9.8 ; 11$ \\
\hline MUFA (g) & 34 & 18 & 21 & 9.1 & 13 & 38 & $12 ; 14$ \\
\hline PUFA (g) & 18 & 11 & 11 & 5.9 & 6.3 & 35 & $5.9 ; 6.7$ \\
\hline Cholesterol (mg) & 332 & 220 & 212 & 114 & 120 & 36 & $112 ; 128$ \\
\hline Carbohydrate (g) & 276 & 122 & 174 & 68 & 103 & 37 & $98 ; 107$ \\
\hline Fibre $(\mathrm{g})$ & 18 & 10 & 11 & 6.4 & 6.6 & 37 & $6.2 ; 6.9$ \\
\hline Alcohol (g) & 9.9 & 28 & 3.4 & 7.1 & 6.5 & 66 & $5.3 ; 7.7$ \\
\hline Vitamin $\mathrm{A}(\mu \mathrm{g} R \mathrm{R})$ & 1146 & 1220 & 806 & 889 & 341 & 30 & $306 ; 376$ \\
\hline Carotene ( $\mu \mathrm{g} R E)$ & 542 & 754 & 388 & 510 & 154 & 28 & $133 ; 176$ \\
\hline Thiamin (mg) & 1.8 & 0.91 & 1.2 & 0.53 & 0.68 & 38 & $0.64 ; 0.71$ \\
\hline Riboflavin (mg) & 2.2 & 1.1 & 1.5 & 0.72 & 0.70 & 32 & $0.66 ; 0.74$ \\
\hline Vitamin $B_{6}(\mathrm{mg})$ & 2.1 & 1.2 & 1.4 & 0.76 & 0.71 & 34 & $0.67 ; 0.75$ \\
\hline Vitamin C (mg) & 103 & 97 & 73 & 60 & 30 & 29 & 27; 34 \\
\hline Calcium (mg) & 834 & 499 & 601 & 331 & 233 & 28 & $214 ; 252$ \\
\hline Iron (mg) & 17 & 9.8 & 11 & 6.0 & 6.7 & 39 & $6.4 ; 7.0$ \\
\hline
\end{tabular}

* Difference $=$ reported portion size minus standard portion size.

†Difference as percentage of the nutrient intake obtained by reported portion size.

Table 3b Mean difference of the energy and nutrient intake obtained by reported portion size and standard portion size in female CSFII participants $(n=1504)$

\begin{tabular}{|c|c|c|c|c|c|c|c|}
\hline & \multicolumn{2}{|c|}{ Reported portion size } & \multicolumn{2}{|c|}{ Standard portion size } & \multicolumn{3}{|c|}{ Difference* $^{*}$} \\
\hline & Mean & SD & Mean & SD & Mean & $\% \dagger$ & $95 \% \mathrm{Cl}$ \\
\hline Energy (kcal) & 1556 & 599 & 1275 & 438 & 281 & 18 & 258; 304 \\
\hline Protein $(\mathrm{g})$ & 62 & 26 & 53 & 20 & 8.1 & 13 & $7.1 ; 9.1$ \\
\hline Total fat (g) & 58 & 29 & 48 & 21 & 9.6 & 17 & $8.5 ; 11$ \\
\hline SFA (g) & 19 & 11 & 16 & 7.7 & 2.9 & 15 & $2.6 ; 3.3$ \\
\hline MUFA (g) & 22 & 11 & 18 & 8.2 & 3.9 & 18 & $3.5 ; 4.3$ \\
\hline PUFA (g) & 12 & 7.7 & 10 & 5.7 & 2.0 & 17 & $1.7 ; 2.3$ \\
\hline Cholesterol (mg) & 215 & 155 & 180 & 107 & 35 & 16 & $30 ; 40$ \\
\hline Carbohydrate (g) & 198 & 83 & 159 & 62 & 39 & 20 & $36 ; 42$ \\
\hline Fibre $(\mathrm{g})$ & 13 & 7.3 & 11 & 5.9 & 2.4 & 18 & $2.2 ; 2.6$ \\
\hline Alcohol (g) & 3.0 & 11 & 1.4 & 4.1 & 1.6 & 53 & $1.2 ; 2.1$ \\
\hline Vitamin $\mathrm{A}(\mu \mathrm{g} \mathrm{RE})$ & 950 & 1338 & 809 & 884 & 141 & 15 & $95 ; 188$ \\
\hline Carotene ( $\mu \mathrm{g} \mathrm{RE})$ & 488 & 745 & 414 & 544 & 74 & 15 & $50 ; 98$ \\
\hline Thiamin (mg) & 1.3 & 0.64 & 1.0 & 0.46 & 0.23 & 18 & $0.21 ; 0.25$ \\
\hline Riboflavin (mg) & 1.5 & 0.82 & 1.3 & 0.65 & 0.19 & 13 & $0.16 ; 0.22$ \\
\hline Vitamin $B_{6}(\mathrm{mg})$ & 1.4 & 0.77 & 1.3 & 0.65 & 0.18 & 13 & $0.16 ; 0.21$ \\
\hline Vitamin C (mg) & 85 & 75 & 75 & 58 & 11 & 13 & $8.2 ; 13$ \\
\hline Calcium (mg) & 601 & 342 & 566 & 314 & 35 & 5.8 & $22 ; 48$ \\
\hline Iron (mg) & 12 & 6.5 & 9.4 & 5.0 & 2.4 & 20 & $2.2 ; 2.6$ \\
\hline
\end{tabular}

* Difference $=$ reported portion size minus standard portion size.

$\dagger$ Difference as percentage of the nutrient intake obtained by reported portion size.

consequences of using standard portion sizes instead of reported portion sizes on the subject's nutrient intake. This enabled us to determine whether standard portion sizes were able to replace missing portion sizes in the ACLS data set.

The results of the ACLS demonstrated that the dietary record using standard portion sizes provided significantly lower energy and nutrient intakes $(\geqslant 20 \%)$ than the same record using reported portion sizes. Because nutrient values obtained using standard portion sizes were consistently lower, and lower than expected for healthy, freeliving individuals, it appears that the use of standard portion sizes may seriously underestimate the mean nutrient intake of the group. However, the correlations between the two methods of portion sizes estimations were relatively high, with all correlations above 0.67. Furthermore, the agreement between both methods was fairly good. The percentage of subjects in the same or adjacent quintile was above $80 \%$ and the percentage of extreme misclassification was below $1 \%$. Therefore, the use of standard portion sizes rather than reported portion sizes may not be suitable to assess the absolute intake at the group level, but may lead to a good ranking of individuals according to nutrient intake. 
Table 4a Spearman correlation coefficients and quintile analyses between energy and nutrient intakes obtained by the reported portion size and by the standard portion size in male CSFII participants $(n=1504)$

\begin{tabular}{|c|c|c|c|c|}
\hline & $\begin{array}{c}\text { Spearman correlation } \\
\text { coefficients }\end{array}$ & Same quintile (\%) & $\begin{array}{c}\text { Same + adjacent } \\
\text { quintile (\%) }\end{array}$ & Extreme quintile (\%) \\
\hline Energy (kcal) & 0.63 & 38 & 78 & 0.6 \\
\hline Protein (g) & 0.61 & 39 & 77 & 0.8 \\
\hline Total fat (g) & 0.72 & 44 & 84 & 0.3 \\
\hline SFA (g) & 0.74 & 46 & 84 & 0.3 \\
\hline $\operatorname{MUFA}(g)$ & 0.74 & 45 & 84 & 0.1 \\
\hline PUFA (g) & 0.76 & 46 & 86 & 0.3 \\
\hline Cholesterol (mg) & 0.80 & 47 & 90 & 0.4 \\
\hline Carbohydrate (g) & 0.69 & 42 & 82 & 1.0 \\
\hline Fibre $(\mathrm{g})$ & 0.78 & 46 & 87 & 0.2 \\
\hline Vitamin $A(\mu g R E)$ & 0.87 & 57 & 94 & 0.0 \\
\hline Carotene ( $\mu \mathrm{g}$ RE) & 0.91 & 61 & 97 & 0.0 \\
\hline Thiamin (mg) & 0.71 & 43 & 82 & 0.5 \\
\hline Riboflavin (mg) & 0.72 & 42 & 82 & 0.3 \\
\hline Vitamin $B_{6}(\mathrm{mg})$ & 0.75 & 47 & 85 & 0.4 \\
\hline Vitamin C (mg) & 0.87 & 56 & 95 & 0.0 \\
\hline Calcium (mg) & 0.73 & 45 & 84 & 0.3 \\
\hline Iron (mg) & 0.75 & 43 & 84 & 0.3 \\
\hline
\end{tabular}

Table 4b Spearman correlation coefficients and quintile analyses between energy and nutrient intakes obtained by the reported portion size and by the standard portion size in female CSFII participants $(n=1504)$

\begin{tabular}{lcccc}
\hline & $\begin{array}{c}\text { Spearman correlation } \\
\text { coefficients }\end{array}$ & Same quintile (\%) & $\begin{array}{c}\text { Same+adjacent } \\
\text { quintile (\%) }\end{array}$ & Extreme quintile (\%) \\
\hline Energy (kcal) & 0.69 & 42 & 81 & 0.7 \\
Protein (g) & 0.67 & 42 & 81 & 0.9 \\
Total fat (g) & 0.75 & 47 & 86 & 0.5 \\
SFA $(\mathrm{g})$ & 0.78 & 49 & 88 & 0.3 \\
MUFA (g) & 0.77 & 47 & 87 & 0.5 \\
PUFA (g) & 0.79 & 48 & 88 & 0.1 \\
Cholesterol (mg) & 0.83 & 53 & 91 & 0.1 \\
Carbohydrate $(\mathrm{g})$ & 0.74 & 47 & 85 & 0.5 \\
Fibre $(\mathrm{g})$ & 0.80 & 51 & 89 & 0.3 \\
Vitamin A $(\mu \mathrm{g} \mathrm{RE})$ & 0.87 & 60 & 94 & 0.0 \\
Carotene $(\mu \mathrm{g} \mathrm{RE})$ & 0.92 & 48 & 98 & 0.0 \\
Thiamin $(\mathrm{mg})$ & 0.76 & 47 & 86 & 0.2 \\
Riboflavin $(\mathrm{mg})$ & 0.77 & 50 & 87 & 0.3 \\
Vitamin $\mathrm{B}_{6}(\mathrm{mg})$ & 0.80 & 56 & 89 & 0.3 \\
Vitamin C $(\mathrm{mg})$ & 0.87 & 48 & 93 & 0.0 \\
Calcium $(\mathrm{mg})$ & 0.77 & 49 & 87 & 0.4 \\
Iron $(\mathrm{mg})$ & 0.77 & & 87 & 0.3 \\
\hline
\end{tabular}

The results of the ACLS were compared with the findings of the CSFII because the CSFII methodology for the assessment of portion sizes was obtained under more rigidly controlled conditions than in the clinical setting of the ACLS. In-person interviews at home were conducted and measuring guides were used to aid the participant in the determination of the portion size. Two findings were noteworthy. First, in the CSFII study the standard portion size also provided lower estimates than the reported portion size for energy and nutrient intakes. This result confirms the finding of the ACLS that the use of standard portion sizes appears to underestimate the mean nutrient intake of the group. Second, reported portion sizes in the CSFII study provided similar energy and nutrient intakes as in the ACLS study.

The findings of the ACLS and CSFII agree well with the studies of Clapp et $a l^{2}$ and Samet et al. ${ }^{6}$. Both studies found significant lower nutrient intakes ( $>26 \%$ ) calculated from a food frequency questionnaire (FFQ) using standard portion sizes compared with intakes calculated from the same FFQ using reported portion size information. Furthermore, in both studies high correlations $(\geqslant 0.73)$ and high exact agreement between tertile classifications $(\geqslant 72 \%)$ were found. Tjonneland et al $^{7}$, however, have shown small differences $(\leqslant 10 \%$ in men and $\leqslant 9 \%$ in women) between food frequency data using photo portion size information and standard portion sizes. No studies were found in which diet records or recalls were used to investigate the effect of substituting standard portion sizes for reported portion sizes on nutrient intake.

Since the energy and nutrient intake obtained by standard portion sizes was consistently underestimated and the variation in the percentage of underestimation was 
small, we decided to adjust the standard portion sizes for energy intake using a correction factor (see Methods section above). Comparison of reported versus adjusted standard portion sizes demonstrated that the differences in energy and nutrient intake $(\leqslant 13 \%)$ were largely reduced. However, for about half of the dietary components, the differences were still significant. This might be partly explained by the large number of subjects involved in the present study, which increases the statistical power to detect small differences in nutrient intake.

In conclusion, the nutrient intake obtained by standard portion sizes was largely underestimated compared to the nutrient intake obtained by reported portion sizes in the ACLS, which was confirmed by the CSFII study. Based on these findings, the standard portion sizes were adjusted for energy intake using the correction factor, which considerably improved the comparability. Thus, the use of adjusted standard portion sizes, in contrast to the use of standard portion sizes, appears to lead to a reasonable assessment of the absolute intake at the group level as well as a good classification of subjects into categories of nutrient intake. This implies that the adjusted standard portion sizes may be able to replace missing portion sizes in the ACLS data set.

\section{Acknowledgements}

This research was supported in part by grants from the National Institute on Aging (AG06945) and from Kellogg's. We thank all the patients from the Cooper Clinic for their ongoing participation, the Cooper Clinic physicians and nutrition department staff for assistance with data collection, and Melba Morrow for editorial assistance.

\section{References}

1 Chu SY, Kolonel LN, Hankin JH, Lee J. A comparison of frequency and quantitative dietary methods for epidemiologic studies of diet and disease. Am. J. Epidemiol. 1984; 119: 323-34.

2 Clapp JA, McPherson RS, Reed DB, Hsi BP. Comparison of a food frequency questionnaire using reported vs standard portion sizes for classifying individuals according to nutrient intake. J. Am. Diet. Assoc. 1991; 91: 316-20.

3 Humble CG, Samet JM, Skipper BE. Use of quantified and frequency indices of vitamin A intake in a case-control study of lung cancer. Int. J. Epidemiol. 1987; 16: 341-6.

4 Hunter DJ, Sampson L, Stampfer MJ, Colditz GA, Rosner B, Willett WC. Variability in portion sizes of commonly consumed foods among a population of women in the United States. Am. J. Epidemiol. 1988; 127: 1240-9.

5 Nelson M, Atkinson M, Darbyshire S. Food photography II: use of food photographs for estimating portion size and the nutrient content of meals. Br.J. Nutr. 1996; 76: 31-49.

6 Samet JM, Humble CG, Skipper BE. Alternatives in the collection and analysis of food frequency interview data. Am.J. Epidemiol. 1984; 120: 572-81.

7 Tjonneland A, Haroldsdottir J, Overvad K, Stripp C, Ewertz $\mathrm{M}$, Jensen OM. Influence of individually estimated portion size data on the validity of a semiquantitative food frequency questionnaire. Int. J. Epidemiol. 1992; 21: 770-7.

8 Fogelholm M, Lahti-Koski M. The validity of a food use questionnaire in assessing the nutrient intake of physically active young men. Eur. J. Clin. Nutr. 1991; 45: 267-72.

9 Food Intake Analysis System, Version 3.0. The University of Texas-Houston, School of Public Health, Houston, TX, 1996.

10 SAS Institute Inc. SAS/STAT User's Guide, Version 6, 4th edn. Cary, NC: SAS Institute Inc., 1989.

11 National Technical Information Service, US Department of Commerce, US Department of Agriculture, Agricultural Research Service. 1994 Continuing Survey of Food Intakes by Individuals and 1994 Diet and Health Knowledge Survey. CD-ROM, accession no. PB96-501010. Springfield, VA: National Technical Information Service, US Department of Commerce, 1996. 